\title{
COMO COZER PÃEZINHOS: PROCESSOS DE RACIOCÍNIO MATEMÁTICO E AÇÕES DO PROFESSOR NA DISCUSSÃO COLETIVA DE UMA TAREFA EXPLORATÓRIA NO 3. ANO
}

\author{
HOW TO BAKE BREADS: MATHEMATICAL REASONING PROCESSES AND TEACHER ACTIONS

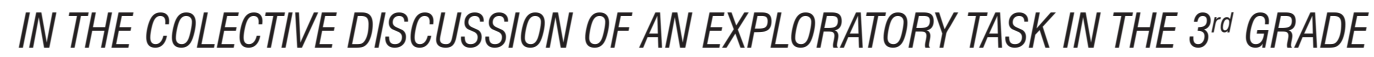

\author{
ELIANE MARIA DE OLIVEIRA ARAMAN ${ }^{1}$ \\ MARIA DE LURDES SERRAZINA ${ }^{2}$
}

\section{RESUMO}

Este estudo apresenta os resultados de uma pesquisa realizada com alunos do $3^{\circ}$ ano do $1^{0}$ Ciclo do Ensino Básico de uma escola pública da periferia de Lisboa. Considerando o raciocínio matemático como uma importante competência a ser desenvolvida desde os primeiros anos, buscamos analisar algumas estratégias de resolução de uma tarefa de natureza exploratória apresentadas por cinco alunos, os processos de raciocínio matemático evidenciados por eles ao resolverem a tarefa e as ações desempenhadas pela professora da turma ao promover a discussão da tarefa na lousa. Trata-se de uma pesquisa qualitativa de carácter interpretativo e os dados foram coletados a partir da gravação em áudio e vídeo da aula. Os resultados mostram que os alunos mobilizaram os processos de conjecturar, perceber padrões, justificar e generalizar. Com relação às ações da professora, elas podem ser classificadas em quatro categorias: Convidar; Guiar/Apoiar; Informar/Sugerir e Desafiar.

Palavras-chave: Raciocínio Matemático. Processos de Raciocínio. Ações do Professor. $1^{0}$ Ciclo do Ensino Básico.

\section{ABSTRACT}

This study presents the results of a research carried out with students of the $3^{\text {rd }}$ grade of the ${ }^{1 \text { st }}$ Cycle of Basic Education of a public school in the periphery of Lisbon. Considering mathematical reasoning as an important ability to be developed since the early years, we analyze some strategies for solving an exploratory task presented by five students, the mathematical reasoning processes evidenced by them when solving the task and the actions performed by class teacher when promoting discussion of the task on the blackboard. The research followed a qualitative interpretative methodology and the data were collected from the audio and video recording of the class. The results show that pupils mobilized the processes of conjecturing, identification of patterns, justifying and generalizing. Regarding the teacher's actions, they were carried out in four categories: Invite; Guide/Support; Inform/Suggest and Challenge.

Keywords: Mathematical reasoning. Reasoning Processes. Teacher Actions. $1^{\text {st }}$ Cycle of Basic Education.

1 Doutora em Ensino de Ciências e Educação Matemática. Universidade Tecnológica Federal do Paraná. E-mail: elianearaman@utfpr.edu.br. Orcid: 0000-0002-1808-2599

2 Doutora em Educação Matemática pela Universidade de Londres (UK). Escola Superior de Educação do Instituto Politécnico de Lisboa, UIDEF, Instituto de Educação, Universidade de Lisboa. E-mail: Iurdess@eselx.ipl.pt. Orcid: 0000-0003-3781-8108 


\section{INTRODUÇÃO}

Para que os alunos ampliem sua capacidade de pensar e mobilizem processos de raciocínio matemático é importante organizar ambientes de ensino e de aprendizagem da Matemática que envolvam a resolução de tarefas desafiantes (PONTE, 2005, 2014) e proporcionar oportunidades de discussão coletiva das tarefas (WOOD, 1999; PONTE, 2017; RODRIGUES; MENEZES; PONTE, 2018, STEIN et al., 2008). Tais ações, quando coordenadas de forma articulada pelo professor, criam ambientes nos quais os alunos apresentam suas ideias, suas estratégias de resolução e justificam suas escolhas.

Para diversos autores cujas pesquisas têm como foco o raciocínio matemático (LANNIN; ELLIS; ELLIOT, 2011; PONTE; MATA-PEREIRA; HENRIQUES, 2012; JEANNOTTE; KIERAN, 2017; MATA-PEREIRA; PONTE, 2018; MORAIS; SERRAZINA; PONTE, 2018), ele é considerado como uma competência básica na aprendizagem de matemática, em todos os níveis de escolaridade.

Entretanto, implementar abordagens de ensino e de aprendizagem de matemática que envolvam as características mencionadas - tarefas de natureza exploratória e discussão delas entre alunos e professores - em salas de aula regulares continua a ser um problema em Educação Matemática (LITHNER, 2008).

Dessa forma, o presente artigo apresenta um episódio de ensino realizado em uma turma regular de $3^{\circ}$ ano do $1^{\circ}$ Ciclo de Ensino Básico (CEB) de uma escola pública da periferia de Lisboa, no qual os alunos resolveram uma tarefa de natureza exploratória que foi amplamente discutida pela professora na turma. Entendemos que a condução da discussão realizada pela professora abarca diversas ações que apoiam o raciocínio matemático de seus alunos (ARAMAN; SERRAZINA; PONTE, 2019).

Tendo em vista tais considerações, a pesquisa ora apresentada tem como objetivo analisar as estratégias de resolução de uma tarefa exploratória feitas por cinco alunos de uma turma de $3^{\circ}$ ano do $1^{\circ}$ Ciclo de Ensino Básico, os processos de raciocínio mobilizados por eles e as ações desempenhadas pela professora durante a discussão da tarefa na lousa.

\section{RACIOCÍNIO MATEMÁTICO E SEUS PROCESSOS}

A expressão raciocínio matemático apresenta uma certa polissemia, sendo entendida de várias formas por vários pesquisadores (JEANNOTTE; KIERAN, 2017). No entanto, no âmbito da Educação Matemática, as compreensões são convergentes e alicerçadas numa essência comum, que é a produção de conhecimento novo a partir de outro já existente, como pode ser visto no Quadro 1:

Quadro 1 - Algumas definições para raciocínio matemático.

\begin{tabular}{|l|c|}
\hline \multicolumn{1}{|c|}{ Definição } & \multicolumn{1}{|c|}{ Referência } \\
\hline $\begin{array}{l}\text { Processo de inferência como o que utiliza informação matemática já conhecida para obter novo } \\
\text { conhecimento ou novas conclusões. }\end{array}$ & STYLIANIDES (2009) \\
\hline $\begin{array}{l}\text { Processo conjunto de conjecturar, generalizar, investigar o porquê, argumentar e refutar se } \\
\text { necessário. }\end{array}$ & LANNIN; ELLIS; ELLIOT (2011) \\
\hline $\begin{array}{l}\text { "Processo de comunicação com outros ou consigo mesmo que permite inferir enunciados } \\
\text { matemáticos a partir de outros enunciados matemáticos". }\end{array}$ & JEANNOTTE; KIERAN (2017, p. 7) \\
\hline $\begin{array}{l}\text { Processo que utiliza "informação já conhecida para obter, justificadamente, novas conclusões”. } \\
\text { Um conjunto de processos mentais complexos através dos quais se obtêm novas proposições } \\
\text { (conhecimento novo) a partir de proposições conhecidas ou assumidas como verdadeiras } \\
\text { (conhecimento prévio). }\end{array}$ & MATA-PEREIRA; PONTE (2018, p. 782) \\
\hline
\end{tabular}

Fonte: Araman e Serrazina (2020, p. 119). 
Para além da definição de raciocínio matemático, Jeannotte e Kieran (2017) consideram dois aspectos importantes: 0 estrutural e 0 de processo. Com relação ao aspecto estrutural, este apresenta uma natureza estática e compreende os diferentes tipos de raciocínio: dedutivo, indutivo e abdutivo (JEANNOTE; KIERAN, 2017). Já o aspecto de processo apresenta natureza dinâmica e temporal e compreende vários tipos de processos. 0 aspecto de processo é o foco deste trabalho e é o que vamos discutir. Entretanto, vale destacar que Jeannotte e Kieran (2017, p. 7) consideram que "os aspectos estrutural e de processos do raciocínio matemático são dois modos diferentes de olhar para um dado discurso". Os processos associados ao raciocínio matemático identificados na literatura indicam:

(i) buscar por semelhanças ou diferenças, que inclui generalização, conjectura, identificação de padrões, comparação e classificação; (ii) validação, ou seja, processos de justificação e prova; e (iii) exemplificação, que apoia os dois anteriores (ARAMAN; SERRAZINA; PONTE, 2019, p. 468).

De acordo com Lannin, Ellis e Elliot (2011) os processos de raciocínio matemático envolvem conjecturar, generalizar, investigar o porquê e desenvolver e avaliar argumentos. Segundo Jeannotte e Kieran (2017) formular conjecturas é um processo cíclico que inclui: (i) enunciar a conjectura; (ii) verificar se cobre todos os casos e exemplos; (iii) tentar refutar; e (iv) encontrar um motivo que faça com que a conjectura seja verdadeira ou tentar modificá-la. Para Morais, Serrazina e Ponte (2018, p. 555), conjecturar é "um processo que envolve raciocínio sobre relações matemáticas, desenvolvendo declarações, nomeadas como conjecturas, que requerem maior exploração para verificar se são verdadeiras ou não verdadeiras".

Ao formular uma conjectura, 0 aluno precisa raciocinar sobre as relações matemáticas e desenvolver afirmações sobre elas. Essas afirmações têm 0 intuito de serem verdadeiras, mas os alunos ainda não sabem se são. Ao observar as relações e pensar sobre elas, os alunos identificam pontos comuns entre vários casos que os ajudam na compreensão do significado de conceitos, símbolos e representações. Ao elaborar uma estratégia de resolução, os alunos formulam conjecturas, mesmo que de forma inconsciente, pois, ao definir um procedimento a ser usado, julgam que este caminho os conduzirá a um resultado (ARAMAN; SERRAZINA, 2020).

Os alunos podem criar conjecturas válidas ou inválidas, alicerçadas em raciocínios válidos ou, por vezes, inválidos. Embora os raciocínios inválidos não sejam desejados, eles podem servir como ponto de partida para o entendimento das ideias matemáticas. Uma conjectura pode ser apresentada de várias formas ou até mesmo existir apenas na mente dos alunos.

No que diz respeito a generalização, de acordo com Lannin, Ellis e Elliot (2011), os alunos generalizam quando se focam numa ideia ou num aspecto particular de um problema, pensam nele de uma forma mais abrangente e consideram duas etapas importantes: identificar os elementos comuns e alargar o domínio do qual se partiu. Os autores destacam também que as generalizações não precisam, necessariamente, envolver estruturas algébricas ou equações.

Seguindo este mesmo entendimento, Ponte, Mata-Pereira e Henriques (2012, p. 3) consideram que a generalização "parte de uma conclusão ou conjectura específica para formular uma conjectura de âmbito mais geral". Para além de afirmações sobre objetos particulares, "a Matemática procura fazer afirmações gerais sobre grandes classes de objetos. Por isso, a generalização constitui uma modalidade particularmente importante de formulação de conjeturas" (MATA-PEREIRA, 2018, p. 78). 
Comparar é um processo que procura, por meio da percepção de semelhanças e diferenças, construir uma narrativa sobre objetos ou relações matemáticas. Ao comparar exemplos, 0 aluno pode conseguir enunciar uma conjectura. Este processo pode ocorrer junto com outros processos de raciocínio matemático como generalizar, identificar um padrão ou validar. 0 processo de classificar, na compreensão de Jeannotte e Kieran (2017), é um processo que procura justificar conjecturas de forma objetiva, tendo como base propriedades e definições matemáticas já estabelecidas.

Com relação aos processos de validação, o processo de justificar requer que os alunos apresentem motivos pelos quais suas conjecturas podem ser válidas ou não, de forma que possam revisar suas conjecturas, aprimorando-as ou refutando-as quando necessário (LANNIN; ELLIS; ELLIOT, 2011).

Para Jeannotte e Kieran (2017, p. 12), "justificar é um processo social e pode assumir dois formatos: (i) justificar a conjectura que surgiu no processo e (2) relatar a validade que altera o valor epistêmico". 0 processo de justificar requer que o aluno não apenas mostre que uma afirmação é verdadeira, mas que forneça razões pelas quais ela é verdadeira ou válida em todos os casos possíveis. Dessa forma, o processo de justificar possibilita que os alunos "não apenas desenvolvem suas habilidades de raciocínio, mas também seu entendimento conceitual” (MORAIS; SERRAZINA; PONTE, 2018, p. 556).

Por fim, exemplificar é considerado por Jeannotte e Kieran (2017) como um processo que serve de suporte aos demais, uma vez que auxilia na pesquisa de semelhanças e diferenças como a validação.

No que tange à mobilização desses processos, Rodrigues, Menezes e Ponte $(2018$, p. 399) indicam a relevância dos momentos de discussões matemáticas como favorecendo 0 "envolvimento [dos alunos] na apresentação, justificação, argumentação e negociação de significados para os seus raciocínios". Wood (1997) também compartilha dessa ideia ao afirmar que é necessário criar um ambiente matemático onde os alunos possam expressar seus pensamentos e que o raciocínio matemático melhor se desenvolve em classes onde as interações e discussões são frequentes.

Além disso, Morais, Serrazina e Ponte (2018, p. 556) recomendam que "alunos de diferentes anos escolares podem se envolver em processos de raciocínio matemático". Assim, as formas pelas quais os processos de raciocínio matemático são apresentados podem assumir diferentes modos ao longo da escolaridade.

\section{AÇÕES DE PROFESSORES QUE APOIAM O RACIOCÍNIO MATEMÁTICO}

Promover o raciocínio matemático dos alunos é uma questão importante que precisa ser investigada e as ações desempenhadas pelo professor ocupam um papel central nesse processo (MATA-PEREIRA; PONTE, 2018).

Para Wood (1999) as diferentes interações na sala de aula, seja entre alunos, seja entre estes e o professor, criam diferentes contextos de aprendizagem. De acordo com Ellis, Özgür e Reiten (2018, p. 2), para apoiar a aprendizagem dos alunos, "as discussões em sala de aula devem concentrar-se tanto em ideias matemáticas importantes quanto no desenvolvimento de significados matemáticos por meio de processos comunicativos". Por sua vez Mata-Pereira e Ponte (2018), argumentam sobre a qualidade dessa discussão, afirmando que se "as perguntas são habitualmente mais provocatórias, os alunos esperam ter que dar respostas mais complexas e que envolvam processos de raciocínio" (p. 758).

Nesse contexto, o papel desempenhado pelo professor em tais discussões é fundamental e compreende ações como selecionar tarefas apropriadas, estimular o pensamento dos alunos, estimular que eles expressem seu pensamento e assumam a responsabilidade intelectual de construir 
e defender suas ideias matemáticas. As ações do professor precisam garantir oportunidades de interação, uma vez que "as aulas onde os alunos expressam os seus pensamentos, explicando-os e justificando-0S, constituem ambientes propícios ao desenvolvimento do seu raciocínio matemático" (ARAMAN; SERRAZINA; PONTE, 2019, p. 470).

Encontramos em Ellis, Özgür e Reitem (2019) uma síntese de diversas pesquisas que discutem, de alguma forma, as ações desempenhadas pelo professor em sala de aula. Uma dessas pesquisas citadas foi realizada por Ponte, Mata-Pereira e Quaresma (2013) e refere-se às ações do professor que promovem e/ou apoiam o raciocínio matemático dos alunos. A partir do estudo das ações do professor, organizaram quatro categorias: ações de Convidar, quando os professores fazem questões com a finalidade de inserir os alunos no contexto de discussão; ações de Guiar/Apoiar, em que os professores conduzem os alunos a fornecer explicações sobre como estão pensando; ações de Informar/Sugerir, quando os professores fornecem informações, sugestões, explicações que apoiam o raciocínio dos alunos; e ações de Desafiar, nas quais os professores desafiam os alunos a estender o seu raciocínio matemático, colocando-os na situação de serem eles próprios a avançar em terrenos novos, "seja em termos de representações, da interpretação de enunciados, do estabelecimento de conexões, ou de raciocinar, argumentar ou avaliar" (PONTE; MATA-PEREIRA; QUARESMA, 2013, p. 59).

Partindo dessa pesquisa, Araman, Serrazina e Ponte (2019), elaboraram uma categorização das ações do professor que apoiam o raciocínio matemático, tendo por base modelos de ações do professor apresentados e discutidos por Wood (1997), Ponte, Mata-Pereira e Quaresma (2013) e Ellis, Özgür e Reiten (2018), conforme consta no Quadro 2. As categorias foram nomeadas a partir da categorização proposta por Ponte, Mata-Pereira e Quaresma (2013).

Quadro 2 - Quadro de análise das ações do professor que apoiam o raciocínio matemático.

\begin{tabular}{|c|c|c|}
\hline \multirow{4}{*}{$\begin{array}{l}C \\
A \\
T \\
E \\
G \\
0 \\
R \\
\text { I } \\
A \\
S\end{array}$} & Convidar & $\begin{array}{l}\text { - Solicita respostas para questões pontuais. } \\
\text { - Solicita relatos de como os alunos fizeram. }\end{array}$ \\
\hline & Guiar/Apoiar & $\begin{array}{l}\text { - Fornece pistas aos alunos. } \\
\text { - Incentiva a explicação. } \\
\text { - Conduz o pensamento do aluno. } \\
\text { - Focaliza o pensamento do aluno para fatos importantes. } \\
\text { - Encoraja os alunos e re-dizerem suas respostas. } \\
\text { - Encoraja os alunos a re-elaborarem suas respostas. }\end{array}$ \\
\hline & Informar/Sugerir & $\begin{array}{l}\text { - Valida respostas corretas fornecidas pelos alunos. } \\
\text { - Corrige respostas incorretas fornecidas pelos alunos. } \\
\text { - Re-elabora respostas fornecidas pelos alunos. } \\
\text { - Fornece informações e explicações. } \\
\text { - Incentiva e fornece múltiplas estratégias de resolução. }\end{array}$ \\
\hline & Desafiar & $\begin{array}{l}\text { - Solicita que os alunos apresentem razões (justificativas). } \\
\text { - Propõe desafios. } \\
\text { - Encoraja a avaliação. } \\
\text { - Encoraja a reflexão. } \\
\text { - Pressiona para a precisão. } \\
\text { - Pressiona para a generalização. }\end{array}$ \\
\hline
\end{tabular}

Fonte: Araman, Serrazina e Ponte (2019, p. 476).

A categoria Convidar abarca as ações por meio das quais o professor "solicita informações dos alunos, seja por meio de questões diretas, ou por meio de explicações para o que fez tendo como 
objeto observar como os alunos estão pensando e qual a sua compreensão a respeito daquele tema" (ARAMAN; SERRAZINA; PONTE, 2019, p. 476). Já na categoria Guiar/Apoiar estão as ações em que o professor, por meio de questionamentos ou explicações, "conduz o pensamento do aluno para uma determinada situação ou focaliza fatos importantes ou ainda quando 0 professor fornece pistas aos alunos e os encoraja a pensarem sobre suas respostas" (ARAMAN; SERRAZINA; PONTE, 2019, p. 476).

A categoria Informar/Sugerir inclui as reações do professor às informações fornecidas pelos alunos. São as ações de validar ou corrigir uma resposta dada pelo aluno, reelaborar uma informação dada por eles que esteja incompleta ou necessita de um aprimoramento, fornecer explicações e informações, e solicitar ou apresentar outras estratégias de resolução (ARAMAN; SERRAZINA; PONTE, 2019). A categoria Desafiar abarca as ações nas quais o professor "tenta colocar os alunos em situação desafiadora de modo que estes avancem em seu raciocínio matemático, procurando novas formas de representação, estabelecendo novas conexões, refletindo e avaliando a situação, generalizando e justificando" (ARAMAN; SERRAZINA; PONTE, 2019, p. 476).

É importante esclarecer que, embora as categorias sejam apresentadas em uma certa ordem, não existe obrigatoriedade de sequência entre elas nem de hierarquização. As ações desempenhadas pelos professores não precisam ocorrer necessariamente em todas as interações, mas algumas delas apresentam maior potencial para apoiar o raciocínio matemático.

\section{METODOLOGIA}

0 presente artigo analisa as estratégias de resolução de uma tarefa matemática por 5 alunos de uma turma de $3^{0}$ ano do $1^{0}$ Ciclo de Ensino Básico, com alunos em torno de 9 anos, de uma escola pública de Lisboa (Portugal), bem como os processos de raciocínio evidenciados por estes alunos durante a discussão coletiva da tarefa. A discussão, mediada pela professora da turma, é também objeto de análise, onde se procura evidenciar as ações realizadas por ela ao conduzir tal discussão.

Esta investigação, que segue uma abordagem qualitativa com caráter interpretativo, insere-se num projeto mais amplo que utiliza uma metodologia de investigação baseada em design (COBB; JACKSON; DUNLOP, 2016; PONTE et al., 2016). A coleta de dados se deu por meio da gravação em áudio e vídeo da aula, que posteriormente foi transcrita pelas pesquisadoras. A coleta foi realizada com 0 consentimento livre e esclarecido dos participantes e com a concordância da escola. Os nomes dos alunos e da professora foram alterados de modo a garantir a confidencialidade de suas identidades.

A tarefa foi explorada no dia 01/02/2016 na referida turma composta por 26 alunos e tinha como objetivo desenvolver a flexibilidade de cálculo em problemas de multiplicação. 0 seu enunciado era: Todos os sábados o padeiro do Pão Bom cozinha 800 pãezinhos que dispõe em tabuleiros. Tens uma ideia de quantos tabuleiros precisará?

Os alunos, organizados em pares, trabalharam primeiramente de forma autônoma na realização da tarefa, fazendo registros escritos individuais na folha de resolução. Após a exploração autônoma da tarefa, alguns alunos foram convidados à lousa para apresentar sua resolução. Estes momentos suscitaram discussões conduzidas pela professora, cujas ações desempenhadas nesse momento foram analisadas tendo como embasamento teórico as ações organizadas e elencadas no Quadro 2 (ARAMAN; SERRAZINA; PONTE, 2019). 


\section{RESULTADOS}

Após a exploração da tarefa de forma autônoma pelos alunos, a professora convidou alguns deles para irem à lousa e compartilharem com os demais alunos qual estratégia usaram para resolver. Para efeitos de organização, separamos a discussão em trechos de acordo com cada aluno.

\section{Tales}

0 aluno Tales vai ao quadro e completa a tabela com 15 tabuleiros e 50 pãezinhos.

Figura 1 - Primeiro registro feito por Tales na lousa.

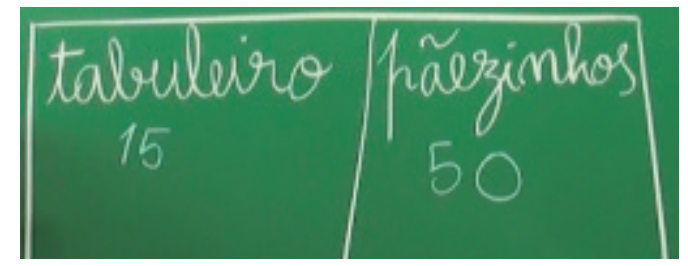

Fonte: Dados da pesquisa.

Professora: 0 que o Tales está a fazer?

Alunos: Está a fazer de $50 \mathrm{em} 50$.

Professora: De $50 \mathrm{em} 50.0$ que ele pensou?

António: Ele pensou de 50 em 50 até 800.

Pedro: Mas não dá! Para 50 pãezinhos precisa de 16 tabuleiros (em seu registro, Tales tinha colocado 15 tabuleiros).

Henrique: Tem que ser 16 vezes 50.

Professora: Deixa o colega continuar (Tales ainda está refazendo seu registro).

Margarida: Se 8 vezes 100 dá 800, então é 16 vezes 50 que dá.

Nesse momento, Tales corrige seu registro, colocando 16 tabuleiros e 50 pãezinhos.

Figura 2 - Segundo registro feito por Tales na lousa.

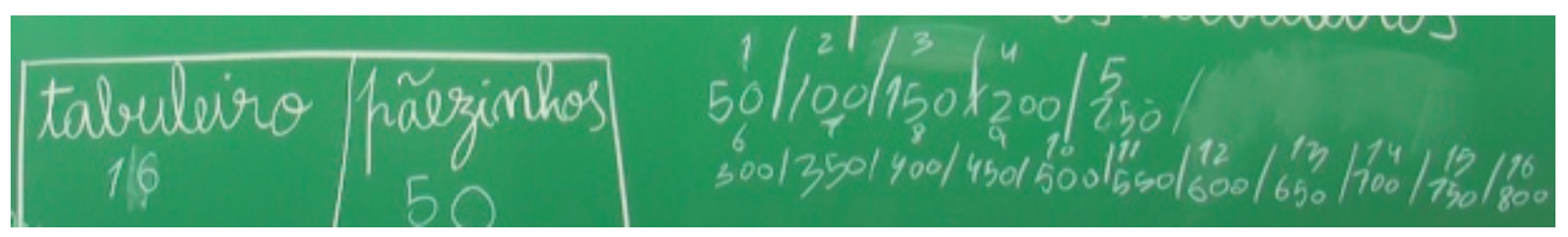

Fonte: Dados da pesquisa.

Professora: 0 Tales chegou a conclusão que são 16 tabuleiros. Esteve bem, que são 16 tabuleiros com 50 pãezinhos. Agora outra possibilidade?

Tales continua na lousa tentando fazer outra possibilidade. 
Figura 3 - Terceiro registro feito por Tales na lousa.

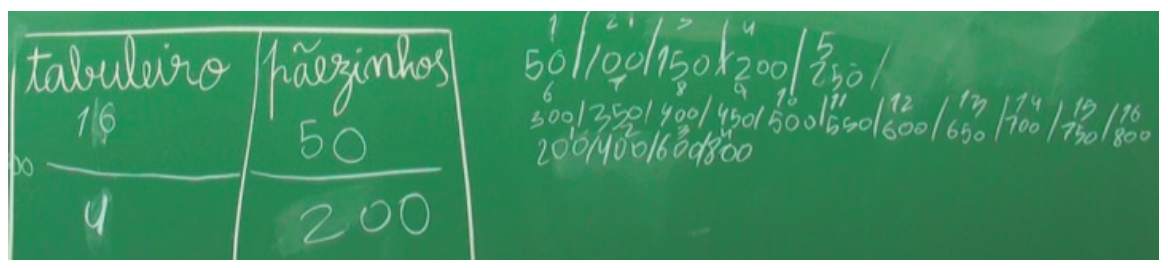

Fonte: Dados da pesquisa.

Professora: Explica lá o que fizeste Tales.

Tales: Agora fui fazendo de 200 em 200, deu 4 vezes 200, 800.

Professora: 4 vezes 200 dá 800, muito bem.

A estratégia usada por Tales, nas duas possibilidades que ele apresentou, foi usar as somas sucessivas até encontrar o valor desejado, no caso, 800. Entretanto, seu primeiro cálculo estava errado, 0 que foi percebido pelos colegas. Ele retornou aos seus cálculos auxiliares (a sequência de 50 em 50) para conferir se eram 15 ou 16 tabuleiros (percebam os números de 1 a 16 que ele anotou em cima da sequência). Quando a professora solicitou outra possibilidade, ele aproveita a mesma estratégia que já usou (somas sucessivas) só que agora de 200 em 200, chegando a 4 tabuleiros.

Quando os colegas afirmam que seu cálculo está errado, ele não aceita imediatamente, retorna aos seus registros para validar essa informação, só depois disso altera seu registro para 16 tabuleiros. Outro aspecto que vale a pena destacar é a relação estabelecida por Margarida (Se 8 vezes 100 dá 800, então é 16 vezes 50 que dá). A afirmação feita por ela pode ser entendida como uma justificativa, baseada em seu entendimento matemático das propriedades da multiplicação.

Com relação às ações da professora, elas estão enquadradas em duas categorias. Em Convidar, quando questiona os alunos sobre como Tales fez e como pensou, e também quando solicita a Tales que faça mais uma possibilidade. Em Informar/Sugerir quando valida as respostas corretas dadas pelos alunos ("De 50 em 50"; "4 vezes 200 dá 800, muito bem”). Entretanto, ela poderia ter explorado a afirmação feita por Margarida ou a relação presente na resolução de Tales, aumentou 4 vezes a quantidade de pãezinhos em cada tabuleiro, então a quantidade de tabuleiros foi dividida por 4.

\section{Laura}

A Laura vai ao quadro e registra sua estratégia de resolução.

Figura 4 - Primeiro registro feito por Laura na lousa.

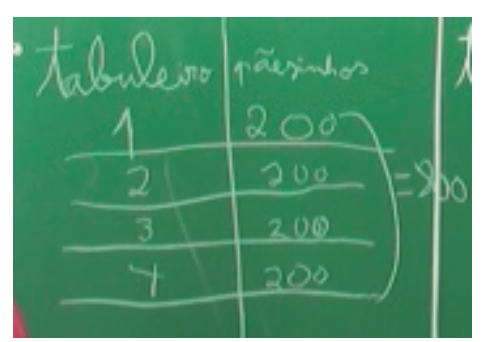

Fonte: Dados da pesquisa. 
Professora: 0 que a Laura esteve a fazer?

Margarida: Esteve a somar.

Bárbara: 0 último está bem.

Professora: Só o último?

Lucas: A Laura não está a fazer direto.

Professora: 0 Lucas está a dizer que a Laura não está a fazer direto e eu quero fazer direto. 0 que quer dizer fazer direto?

Lucas: Direto quer dizer em vez de estar a somar os 200 pode-se fazer direto, pode-se fazer 4 tabuleiros vezes 200 pãezinhos que é igual já a 800, mas ela não fez direto.

Professora: Pronto. Ele diz que ela não fez direto. Ela foi de uma forma indireta. Ela fez como?

Margarida: Ela foi juntando sempre mais 200.

Professora: Juntando 200.

Lucas: Que deu 800.

Professora: Que deu 800. Agora o Lucas vai explicar o que a Laura esteve ali a fazer (se referindo ao segundo registro feito por Laura).

Figura 5 - Segundo registro feito por Laura na lousa.

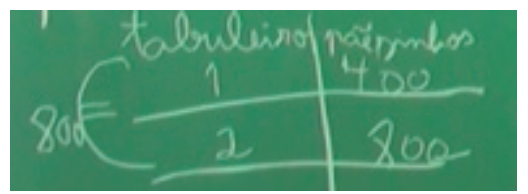

Fonte: Dados da pesquisa.

Lucas: A Laura fez 2 vezes 400 que deu 800 pães.

Professora: Está bem.

Henrique: Ela tinha que ter feito 2 vezes 400.

Figura 6 - Correção do segundo registro feito por Laura na lousa.

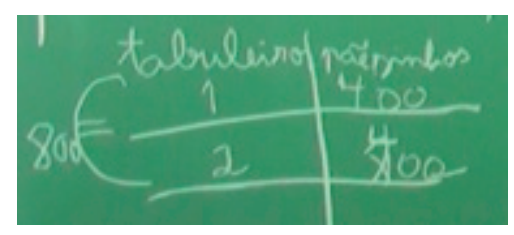

Fonte: Dados da pesquisa.

Professora: A Laura fez uma outra leitura. Explica lá Laura, o que fizeste.

Laura: 400 mais 400 é igual a 800.

Henrique: Está bem agora, 400 mais 400 dá 800.

Margarida: Também podia ser 2 vezes 400 que dá 800.

Professora: Ela fez 1 tabuleiro tem 400, o outro tabuleiro tem mais 400, logo são... 
Alunos: 800.

Professora: A Laura fez todas as suas possibilidades, todas as possibilidades que descobriu, descobriu assim.

A estratégia utilizada por Laura é semelhante a feita por Tales (adições sucessivas), embora os registros escritos sejam diferentes. No primeiro, ela calcula a soma de 4 tabuleiros com 200 pãezinhos cada e no segundo, após a correção, 2 tabuleiros com 400 pãezinhos. Percebam que a relação de dobro e metade também está presente na resolução de Laura, mas não é comentada por ela, pelos colegas ou pela professora. Os colegas questionam quanto a necessidade de se fazer esse tipo de registro, quando ela poderia ter feito "direto", de acordo com eles. Também no caso de Laura, ao escolher uma estratégia de resolução que teve sucesso, ela a aproveita para fazer as demais possibilidades, 0 que pode ser confirmado com a fala da professora "A Laura fez todas as suas possibilidades, todas as possibilidades que descobriu, descobriu assim".

Com relação as ações da professora, vale destacar a importância dela para a discussão da tarefa. Suas ações estão presentes em três categorias. Com relação à categoria Convidar, ela solicita que os alunos relatem como fizeram ("O que a Laura esteve a fazer?"; "Explica lá Laura, o que fizeste.") e também solicita respostas a questões pontuais ("Só o último?”).

$\mathrm{Na}$ categoria Guiar/Apoiar ela incentiva os alunos a fornecerem explicações ("O que quer dizer fazer direto?"; "Ele diz que ela não fez direto. Ela foi de uma forma indireta. Ela fez como?"). Na categoria Informar/Sugerir, ela valida as respostas dadas pelos alunos (": Juntando 200"; "Que deu 800"; "Está bem".)

\section{Gabriel}

A professora solicita que Gabriel vá à lousa e explique como resolveu a tarefa.

Figura 7 - Registro feito por Gabriel na lousa.

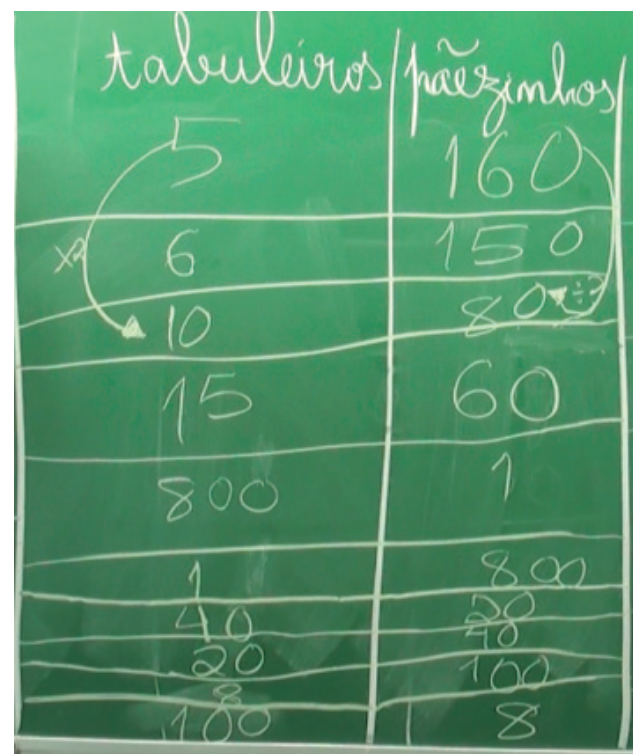

Fonte: Dados da pesquisa. 
Professora: Gabriel, fizestes aquelas todas? Vamos explicar?

Gabriel: Vi que 5 vezes 100 dava 500, depois 5 vezes 60 dava trezentos porque 5 vezes 6 dá 30, então 5 vezes 160 dá 800. (indica a primeira linha de sua tabela).

Professora: Toda a gente concorda?

Alunos: Sim.

Professora: Mas por que é que isso está relacionado com o 10? Explica lá.

Gabriel: Porque 160 é a metade de 80 e...

Professora: 160 é a metade de quê?

Gabriel: É dobro de 80.160 é o dobro de 80 e 80 é a metade de 160. E 5 é metade de 10 e 10 é 0 dobro de 5. Eu vi que 10 vezes 80 dava 800.

Professora: E agora o 6? (se referindo a segunda linha da tabela de Gabriel). 06 com o 150. Quero saber o que fez.

Gabriel: Porque 6 vezes 150 fica...

António: Está mal, pois dá 900.

Pedro: Porque 6 vezes 100 é 600 e 50 vezes 6 é igual a 300, dá 900.

Gabriel: 6 vezes 100 é 600, 50 vezes 6 é 300, dá 900.

Professora: Então qual que deve ser?

João: Tem que ser 16 vezes 50, daí fica bem.

Professora: Por quê?

João: Porque 10 vezes 50 dá 500 e 6 vezes 50 dá 300, então dá 800 .

Professora: E a outra?

Gabriel: 800 vezes 1 está bem, a outra também (se referindo a 1 vezes 800).

Professora: E a outra?

Gabriel: Também está bem, porque 40 é a metade de 80 e 020 é o dobro de 10 (estabelece uma relação de dobro/metade com a $3^{a}$ linha da tabela). Então eu fiz 20 vezes 40 que deu 800, porque 2 vezes 4 é 8, tira-se os zeros, 4 vezes 2 dão 8, depois coloca-se os zeros, 800.

Professora: Porque tiras os zeros?

Gabriel: Para ficar mais fácil de fazer.

Professora: E a debaixo?

Gabriel: É ao contrário.

Professora: 0 que é que se troca ali?

Alunos: As parcelas.

Professora: São as parcelas.

Gabriel: Aqui eu vi que 8 vezes 10 dava 80 e depois acrescentei um zero, deu 800.

Gabriel apresenta mais estratégias de resolução do que Tales e Laura e, além disso, em muitas delas recorre à estratégia de que se dobrar (ou dividir por 2) o multiplicando, pode dividir por 2 (ou dobrar) o multiplicador mantendo o mesmo resultado, ou ainda suprimir os zeros da multiplicação e depois acrescentá-los, evidenciando dominar as propriedades da multiplicação, embora refira "parcelas" quando devia referir "fatores".

Pela discussão com a professora e demais colegas, é possível perceber que, para além de explicar sua resolução, ele apresenta também uma justificativa para ela ("Vi que 5 vezes 100 dava 500, 
depois 5 vezes 60 dava trezentos porque 5 vezes 6 dá 30, então 5 vezes 160 dá 800"; "Então eu fiz 20 vezes 40 que deu 800, porque 2 vezes 4 é 8 , tira-se os zeros, 4 vezes 2 dão 8, depois coloca-se os zeros, 800 ”). Quando 0 colega indica que sua estratégia está errada pois o resultado é 900, ele refaz seu cálculo, aceitando a justificativa apresentada pelo colega.

Com relação às ações da professora, elas se encaixam nas quatro categorias. A todo o momento ela solicita que Gabriel relate o que fez, constituindo ações da categoria Convidar ("Explica lá."; "E agora o 6?"; "E a outra?"). Realiza ações da categoria Guiar/Apoiar ao pedir que 0 aluno forneça explicações ("Então qual deve ser?"; "Por que tiras os zeros?"), da categoria Informar/Sugerir ao corrigir uma resposta dada pelo aluno ("160 é a metade de quêe?"). Destacamos as ações da categoria Desafiar quando ela solicita que 0 aluno apresente justificativas para suas resoluções, questionando o por quê ("Mas por que é que isso está relacionado com o 10?"; "Por quê?”).

\section{António}

António vai à lousa explicar a resolução que fez para a tarefa.

Figura 8 - Registro feito por António na lousa.

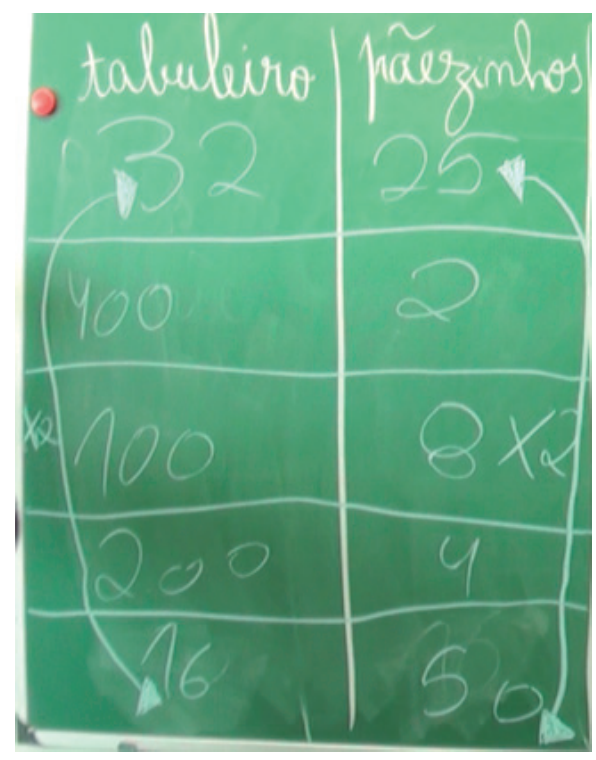

Fonte: Dados da pesquisa.

António: Posso começar a explicar por aqui? (Se refere a última linha da tabela.)

Professora: Pode explicar como quiser.

António: Então, eu fiz 50 pãezinhos vezes 10 que era 500 e 6 vezes 50 que era 300. E mais $300 \mathrm{com}$ 500 que era 800. E depois eu multipliquei o 16 vezes 2 que dá 32 e dividi o 50 por 2 que é o 25 (indica a primeira linha da tabela). Então ficou 32 tabuleiros vezes 25 pãezinhos.

Professora: Esta proposta, esta possibilidade do António está correta?

Alunos: Está. 
Professora: Está correta. 0 que ele esteve ali a fazer?

João: Ele esteve a fazer 16 tabuleiros vezes 50 pãezinhos, depois viu que 32 é o dobro de 16 e 16 é a metade de 32. Depois viu também que o 50 é o dobro de 25 e 25 é a metade de 50.

Professora: Mas olha, como é que ele chegou ao 25 pãezinhos por 32 tabuleiros?

António: Porque é a metade e o dobro.

Professora: É a metade e o dobro de quê?

António: 32 é o dobro de 16 e 16 é a metade de 32 . E 50 é o dobro de 25 e 25 é a metade de 50.

Professora: António, essa relação é isso mesmo, mas como é que tu chegaste? Mas algum colega fez? Pedro: Eu fiz também.

Professora: Como é que tu pensaste para perceber que para 32 tabuleiros dava 25 pãezinhos?

António: Eu vi que 32 vezes 10 era 320, mais vezes 10 era mais 320, 320 mais 320 era 640 e 5 vezes 32 era...

Pedro: Fazes 30 vezes 5 que dá 150.

António: Mais 2 vezes 5 que é 10.

Professora: E qual é que você fez primeiro, o 32 ou o 16 tabuleiros?

António: Fiz primeiro o 50 vezes 16.

Professora: E como é que chegastes a essa conclusão?

António: Porque 50 vezes 10 é 500 e 6 vezes 50 é igual a 300. E por isso eu só multipliquei por 2 e deu 32.

Professora: Aí fizeste os dobros e as metades.

António: Depois disso, 400 vezes 2 que é obvio, depois 100 vezes 8, e depois 200 vezes 4, ou seja, pode multiplicar 200 vezes 2 que é 400 e depois vezes 2 que é 400 .

António também evidencia conhecer as propriedades da multiplicação ou recorrer a relação de dobro e metade para resolver sua tarefa. Em vários momentos ele fornece justificativas para validar sua estratégia de resolução ("Então, eu fiz 50 pãezinhos vezes 10 que era 500 e 6 vezes 5 que era 300. E mais $300 \mathrm{com} 500$ que era 800. E depois eu multipliquei o 16 vezes 2 que dá 32 e dividi o 50 por 2 que é o 25 (indica a primeira linha da tabela). Então ficou 32 tabuleiros vezes 25 pãezinhos."). Em outros momentos, os colegas participam da discussão auxiliando António em suas explicações.

As ações da professora podem agrupar-se nas quatro categorias. Em Convidar, sua ação é muito pontual ao solicitar que António relate o que fez. Já em Guiar/Apoiar, ela incentiva a explicação não somente de António, mas também dos demais alunos ("O que ele esteve ali a fazer?"; "Mas olha, como é que ele chegou ao 25 pãezinhos por 32 tabuleiros?") e focaliza 0 pensamento dos alunos para fatos importantes ("É a metade e o dobro de quê??"). Na categoria Informar/Sugerir, mais uma vez ela valida e reelabora respostas fornecidas pelos alunos ("Está correta."; "Aí fizeste os dobros e as metades."). Na de Desafiar quando questiona E como é que chegastes a essa conclusão? 


\section{Pedro}

Pedro vai até a lousa para mostrar como fez.

Figura 9 - Registro feito por Pedro na lousa.

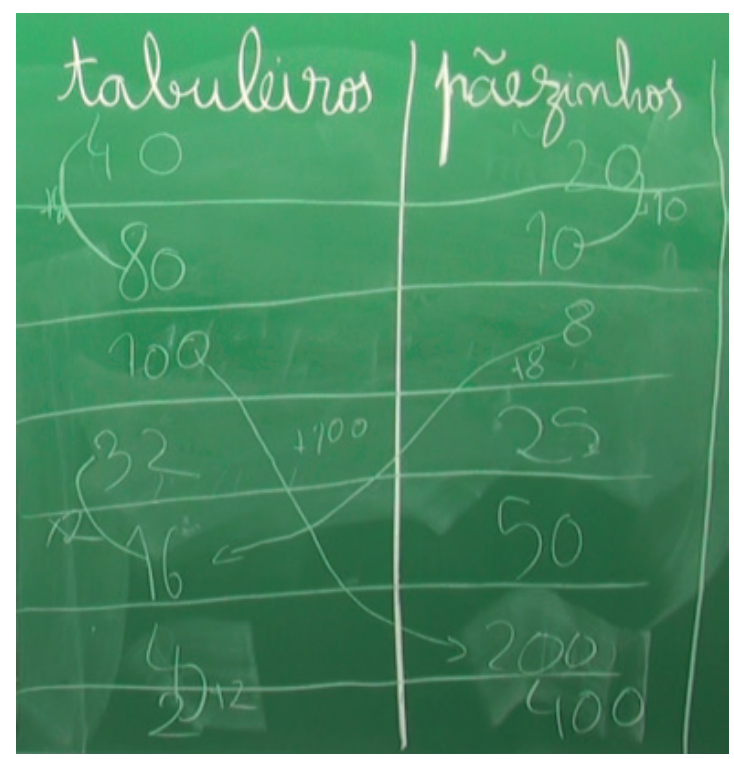

Fonte: Dados da pesquisa.

Professora: Amigo Pedro, explica o teu.

Pedro: Eu fiz 40 vezes 20 que dá 800.

Professora: 0 Pedro esteve a fazer uma coisa lá. Ele fez 40 vezes 20 que é?

Alunos: 800.

Professora: 800. E a seguir faz 80 vezes 10 que dá?

Alunos: 800.

Professora: 800.

Pedro: Aqui é metade e ali é o dobro (se referindo que 40 é a metade de 80 e 20 o dobro de 10).

Professora: Olha lá, se nós analisarmos as linhas o que é que o Pedro esteve a fazer? 40 vezes 20 quanto é que dá?

Alunos: 800.

Professora: 800.

Pedro: Como é que eu fiz, eu tirei o zero do 20 e pus no 40 que deu 400, vezes 2.

Professora: E a seguir?

Pedro: Fiz 100 vezes 8 que deu 800. A seguir fiz 32 vezes 25.

Professora: Como é que fizeste isso assim logo rapidinho?

Pedro: Fiz 30 vezes 20 que é igual a 600, fiz 2 vezes 20 que é igual a 40, somei deu 640. A seguir fui fazer 30 vezes 5 que é igual a 150, e a seguir fiz 2 vezes 5 que é igual a 10. Somei e deu 160. E agora fiz 640 mais 160 que deu 800.

Professora: Alguém tem uma possibilidade diferente daquelas que já estão ali? 
Ricardo: Cheguei a uma conclusão.

Professora: Diz lá Ricardo.

Ricardo: É que sempre, é sempre o dobro. 2 vezes 400 é 800, 4 vezes 200 é 800 . São sempre os dobros.

Professora: 0 que é que são sempre os dobros?

Ricardo: 0 2, o 4, 0 1, 0 8, 0 16, o 32.

Professora: Ora bem.

Pedro: Eu ainda não expliquei todas.

Professora: Então fala lá.

Pedro: Agora fiz 16 vezes 50 que deu 800.

Professora: Então explica isso.

Pedro: Eu fiz 10 vezes 50 que deu 500, depois fiz 6 vezes 50 que é 300 porque se fosse 100 era 600, mas é metade. Depois fiz 300 mais o 500 que é 800.

Professora: Muito bem. E a seguir?

Pedro: A seguir fiz 4 vezes 200 que é igual a 800 e daí fiz 2 vezes 400.

Professora: Alguém tem mais alguma possibilidade?

Alunos: Não.

Professora: Não há mais possibilidades?

Alunos: Não.

Professora: Encontramos todas?

Margarida: Acho que sim!

Professora: E qual é a conclusão, dá para tirar alguma conclusão dali?

Margarida: É tudo dobros e metades.

A resolução de Pedro é semelhante à de Gabriel e António. Ele também utiliza a relação de dobro e de metade ("Aqui é metade e ali é o dobro") e evidencia conhecer as propriedades da multiplicação ao resolver 32 vezes 25, decompondo tanto o multiplicando quanto o multiplicador ("Fiz 30 vezes 20 que é igual a 600, fiz 2 vezes 20 que é igual a 40, somei deu 640. A seguir fui fazer 30 vezes 5 que é igual a 150, e a seguir fiz 2 vezes 5 que é igual a 10. Somei e deu 160. E agora fiz 640 mais 160 que deu 800."). Além de explicar como fez, em alguns momentos ele justifica suas escolhas ("Eu fiz 10 vezes 50 que deu 500, depois fiz 6 vezes 50 que é 300 porque se fosse 100 era 600, mas é metade. Depois fiz 300 mais o 500 que é 800"). 0 aluno Ricardo, diante da percepção de uma regularidade, e expõe ("É que sempre, é sempre o dobro. 2 vezes 400 é 800, 4 vezes 200 é 800 . São sempre os dobros."). Embora 0 aluno não consiga expressar claramente todos os elementos da relação feita por ele, consideramos que ele conseguiu generalizar essa relação, pois a estende para outros valores ("0 2, o 4, o 1, 0 8, o 16, o 32").

No que diz respeito as ações da professora, elas estão enquadradas nas quatro categorias. Novamente, em Convidar, ela solicita que o aluno relate como fez ("Amigo Pedro, explica o teu"; "Diz lá Ricardo"). Em Guiar/Apoiar, ela incentiva que o aluno explique o que fez ("Como é que fizeste isso assim logo rapidinho?"; "Então explica isso.") e conduz o pensamento dos alunos para fatos importantes ("Olha lá, se nós analisarmos as linhas o que é que o Pedro esteve a fazer?"). Já em Informar/Sugerir, ela, assim como nos casos anteriores, valida as respostas corretas fornecidas pelos alunos ("800"; "Muito bem"). Na categoria Desafiar, ela encoraja a reflexão ("0 que é que são sempre os dobros?; "E qual é a conclusão, dá para tirar alguma conclusão dali?"). 


\section{DISCUSSÃO E CONCLUSÃO}

Iniciamos o presente artigo afirmando a necessidade de se trabalhar com tarefas matemáticas que apresentem um potencial para o desenvolvimento cognitivo do aluno (PONTE, 2005), bem como a importância de se criar um ambiente de sala de aula no qual os alunos possam expressar e discutir suas ideias (WOOD, 1997). Os resultados obtidos a partir da análise da discussão promovida pela professora evidenciam que estes dois aspectos foram contemplados. Primeiramente, a tarefa trabaIhada com a turma tem como característica possibilitar várias estratégias de resolução, permitindo aos alunos a escolha de um método próprio de resolução, o que, de acordo com Ponte (2005), é muitas vezes mais eficaz em termos de aprendizagem dos alunos. Acresce que as diversas formas pelas quais os alunos resolveram a questão possibilitou a discussão, o que seria difícil de acontecer se todos resolvessem da mesma forma.

Ao selecionar alguns alunos, que apresentavam resoluções diferentes, para ir à lousa compartiIhar o que fizeram com os demais, a professora mostrou ter em mente a preocupação de compartilhar as diferentes maneiras pelas quais diferentes pessoas podem pensar e resolver problemas (WOOD, 1997), e, ainda que o raciocínio matemático se desenvolve melhor em classes com frequentes situações de discussão que possibilitem trocas entre professor e alunos (STEIN et al., 2008; WO0D, 1999).

As estratégias de resolução apresentadas pelos alunos vão desde as mais simples, recorrendo ao uso de adições sucessivas (feitas por Tales e Laura), até as mais elaboradas, nas quais os demais alunos evidenciaram diversos conhecimentos matemáticos, como as propriedades da multiplicação, mais especificamente a propriedade distributiva da multiplicação em relação à adição, a multiplicação por múltiplos de 10 e a propriedade comutativa (alteravam os fatores e obtinham o mesmo produto). Tais conhecimentos anteriores foram fundamentais para que elaborassem suas estratégias de resolução, evidenciando, assim, o desenvolvimento do raciocínio matemático (JEANNOTTE; KIERAN, 2017), pois, a partir de proposições conhecidas ou assumidas como verdadeiras (conhecimento prévio) obtiveram novas proposições (conhecimento novo) (MORAIS; SERRAZINA; PONTE, 2018).

Com relação aos processos de raciocínio, ao elaborarem suas estratégias de resolução, os alunos elaboraram conjecturas, mesmo que de forma inconsciente, uma vez que, ao definirem um procedimento a ser usado, julgaram que este caminho os conduziria a um resultado (ARAMAN; SERRAZINA, 2020). As conjecturas, em forma de estratégias de resolução, foram apresentadas por eles, com a finalidade de serem validadas ou não. Tal validação se deu pelo processo de justificação, que, de acordo com Lannin, Ellis e Elliot (2011), consiste em os alunos apresentarem motivos pelos quais suas conjecturas podem ser válidas ou não, de forma que possam revisá-las, aprimorando-as ou refutando-as quando necessário. Muitas delas foram validadas durante a discussão e outras foram refutadas, como 0 caso da multiplicação 6 vezes 150 feita por Gabriel que foi refutada por António. Ao fazer isso, António justifica porque aquela estratégia não está correta, conduzindo Gabriel a revisá-la, concordando com a refutação.

Também há a percepção da existência de um padrão, presente na relação dobro/metade, evidenciada em muitos momentos pelos alunos. A partir da percepção desse padrão, e com a ajuda da professora durante a discussão, Ricardo consegue exprimir uma generalização, ao afirmar que é sempre 0 dobro. Para Lannin, Ellis e Elliot (2011), os alunos generalizam quando se focam numa ideia ou num aspecto particular de um problema e pensam nele de uma forma mais abrangente, a partir da 
identificação de elementos comuns e conseguem alargar para o domínio do qual se originou. Os autores destacam também que as generalizações não precisam, necessariamente, envolver estruturas algébricas ou equações. Embora essa generalização ainda não se apresente em sua forma completa, destacamos que estamos diante de uma turma de $3^{\circ}$ ano do $1^{\circ} \mathrm{CEB}$ com alunos em torno de 9 anos.

Quanto às ações da professora, tendo em consideração a categorização apresentada por Araman, Serrazina e Ponte (2019), elas estão distribuídas entre as quatro categorias. Na categoria Convidar, quase que exclusivamente as ações da professora foram de solicitar que os alunos relatassem como fizeram, incluindo ainda algumas questões pontuais. Já quando solicitou que os alunos explicassem como fizeram e ainda quando conduziu ou focalizou a atenção dos alunos para fatos importantes, algumas vezes através de perguntas, estamos perante ações que se enquadram na categoria Guiar/Apoiar. 0 tipo de questionamento em cada categoria se diferencia pela intencionalidade da professora e pela natureza mais profunda da resposta esperada.

Com relação à categoria Informar/Sugerir, suas ações foram concentradas na validação de respostas corretas fornecidas pelos alunos e na correção de algumas que estavam incorretas, com intuito de que os mesmos as corrigissem. Quando, ainda por meio de questionamento, a professora solicitou que os alunos apresentassem razões, ou seja, justificassem o que fizeram e refletissem sobre algum ponto relevante da tarefa incluímos estas ações na categoria Desafiar.

Como referido anteriormente, com relação às categorias apresentadas por Araman, Serrazina e Ponte (2019), não há a necessidade de a professora realizar todas elas numa mesma discussão de tarefa, nem há uma hierarquização da relação de importância entre elas, mas é necessário destacar que algumas tem maior potencial para 0 desenvolvimento do raciocínio matemático. Neste caso, as ações da categoria Desafiar conduziram os alunos a justificarem suas resoluções e, até mesmo, formularem uma generalização. No entanto, para atingir este ponto, foram necessárias muitas outras ações das outras categorias, de tal forma elas contribuem para subsidiar a discussão, conduzindo os alunos a organizarem seu pensamento, se expressarem matematicamente e estabelecerem relações. Ou seja, é este movimento de ir e vir das ações da professora, perpassando por todas as categorias, que apoiam o raciocínio matemático dos alunos (ELLIS; ÖZGÜR; REITEN, 2018).

\section{REFERÊNCIAS}

ARAMAN; E. M. O., SERRAZINA, M. L. Processos de raciocínio matemático na resolução de tarefas exploratórias no $3^{\circ}$ ano de escolaridade. Revista Paranaense de Educação Matemática, v. 9, n. 18, p. 118-136, jan-jun 2020.

ARAMAN, E. M. O.; SERRAZINA, M. L.; PONTE, J. P. "Eu perguntei se o cinco não tem metade": ações de uma professora dos primeiros anos que apoiam o raciocínio matemático. Educação Matemática Pesquisa, v. 21, n. 2, p. 466-490, 2019.

COBB, P.; JACKSON, K.; DUNLAP, C. Design research: an analysis and critique. In: ENGLISH, L. D.; KIRSHNER, D. (Eds.). Handbook of international research in mathematics education. New York, NY: Routledge, 2016. p. 481-503.

ELLIS, A., ÖZGÜR, Z., REITEN, L. Teacher moves for supporting student reasoning. Mathematics Education Research Journal, v. 30, n. 2, p. 1-26, jun. 2018. 
JEANNOTTE, D.; KIERAN, C. A conceptual model of mathematical reasoning for school mathematics. Educational Studies in Mathematics, v. 96, n. 1, p. 1-16, 2017.

LANNIN, J.; ELLIS, A. B.; ELLIOT, R. Developing essential understanding of mathematics reasoning for teaching mathematics in prekindergarten-grade 8. Reston, VA: National Council of Teachers of Mathematics. 2011.

LITHNER, J. A research framework for creative and imitative reasoning. Educational Studies in Mathematics, v. 67, n. 3, p. 255-276, 2008.

MATA-PEREIRA, J. Ações do professor para promover o raciocínio matemático. 2018. 182f. Tese (Doutorado em Educação: Didática da Matemática. Instituto de Educação, Universidade de Lisboa, Lisboa.

MATA-PEREIRA, J.; PONTE, J. P. Promover o Raciocínio Matemático dos Alunos: uma investigação baseada em design. Bolema, v. 32, n. 62, p. 781 - 801, 2018.

MORAIS, C.; SERRAZINA, L.; PONTE, J. P. Mathematical Reasoning Fostered by (Fostering) Transformations of Rational Number Representations. Acta Scientiae, v. 20, n. 4, p. 552 - 570, 2018.

PONTE, J. P. Gestão curricular em Matemática. In: GTI (Ed.) 0 professor e o desenvolvimento curricular. Lisboa: APM, 2005, p. 11-34.

PONTE, J. P. Tarefas no ensino e na aprendizagem da Matemática. In: PONTE, J. P. (Org.). Práticas Profissionais dos Professores de Matemática. Lisboa: Instituto de Educação da Universidade de Lisboa, 2014. p. 13-27.

PONTE, J. P. Discussões coletivas no ensino aprendizagem em Matemática. In: GTI (Ed.). A prática dos professores: planificação e discussão coletiva na sala de aula. Lisboa: APM, 2017, p. 33-56.

PONTE, J. P.; CARVALHO, R.; MATA-PEREIRA, J.; QUARESMA, M. Investigação baseada em design para compreender e melhorar as práticas educativas. Quadrante, v. 25, n. 2, p. 77-98, 2016.

PONTE, J. P.; MATA-PEREIRA, J.; HENRIQUES, A. 0 raciocínio matemático nos alunos do Ensino Básico e do Ensino Superior. Práxis Educativa, v. 7, n. 2, p. 355-377, 2012.

PONTE, J. P.; MATA-PEREIRA, J.; QUARESMA, M. Ações do professor na condução de discussões matemáticas. Quadrante, Lisboa, v. XXII, n. 2, p. 55-81, 2013.

RODRIGUES, C.; MENEZES, L.; PONTE, J. P. Práticas de Discussão em Sala de Aula de Matemática: os casos de dois professores. Bolema, v. 12, n. 61, p. 398-418, 2018.

STEIN, M. K.; ENGLE, R. A.; SMITH, M. S.; HUGHES, E. K. Orchestrating productive mathematical discussions: Five practices for helping teachers move beyond show and tell. Mathematical Thinking and Learning, v. 10, n. 4, p. 313-340, 2008.

STYLIANIDES, G. Reasoning-and-proving in school mathematics textbooks. Mathematical Thinking and Learning, v. 11, n. 4 , p. $258-288,2009$. 
WOOD, T. Creating classroom interactions for mathematical reasoning: beyond "natural teaching". In: ABRANTES, P.; PORFÍRIO, J.; BAÍA, M. (Org.), The interactions in the mathematics classroom, proceedings of the CIEAEM 49. Setúbal: Escola Superior de Educação, 1997, p. 34-43.

WOOD, T. Creating a context for argument in mathematics class. Journal for Research in Mathematics Education, v. 30, n. 2, p. 171-191, 1999.

RECEBIDO EM: 24 jun. 2020

CONCLUÍDO EM: 30 ago. 2020 
